\title{
Toward an integrative understanding of social behavior: new models and new opportunities
}

\section{DanielT. Blumstein ${ }^{*}$, Luis A. Ebensperger ${ }^{2}$, Loren D. Hayes ${ }^{3 *}$, Rodrigo A. Vásquez ${ }^{4}$,Todd H. Ahern ${ }^{5}$, Joseph Robert Burger ${ }^{3 \dagger}$, Adam G. Dolezal ${ }^{6}$, Andy Dosmann 7 , Gabriela González-Mariscal ${ }^{8}$, Breanna N. Harris ${ }^{9}$, Emilio A. Herrera ${ }^{10}$, Eileen A. Lacey ${ }^{11}$, Jill Mateo ${ }^{7}$, Lisa A. McGraw ${ }^{12}$, Daniel Olazábal ${ }^{13}$, Marilyn Ramenofsky ${ }^{14}$, Dustin R. Rubenstein ${ }^{15}$, Samuel A. Sakhai ${ }^{16}$, Wendy Saltzman ${ }^{9}$, Cristina Sainz-Borgo ${ }^{10}$, Mauricio Soto-Gamboa ${ }^{17}$, Monica L. Stewart ${ }^{3}$, Tina W. Wey' ${ }^{1}$ John C. Wingfield ${ }^{14}$ and Larry J. Young ${ }^{5}$}

\author{
Department of Ecology and Evolutionary Biology, University of California Los Angeles, Los Angeles, CA, USA \\ 2 CASEB and Departamento de Ecología, Facultad de Ciencias Biológicas, P. Universidad Católica de Chile, Santiago, Chile \\ ${ }^{3}$ Department of Biology, University of Louisiana at Monroe, Monroe, LA, USA \\ 4 Institute of Ecology and Biodiversity, Departamento de Ciencias Ecologicas, Universidad de Chile, Santiago, Chile \\ 5 Department of Psychiatry, Center for Behavioral Neuroscience, Yerkes National Primate Center, Emory University School of Medicine, Atlanta, GA, USA \\ 6 School of Life Sciences, Arizona State University, Phoenix, AZ, USA \\ 7 Committee on Evolutionary Biology, University of Chicago, Chicago, IL, USA \\ ${ }^{8}$ Centro de Investigacion en Reproduccion Animal, Centro de Investigación y de Estudios Avanzados del Instituto Politécnico Nacional, Universidad Autónoma de \\ Tlaxcala, Tlaxcala, México \\ ${ }^{9}$ Department of Biology, University of California Riverside, Riverside, CA, USA \\ ${ }^{10}$ Departamento de Estudios Ambientales, Universidad Simón Bolívar, Caracas, Venezuela \\ "Department of Integrative Biology and Museum of Vertebrate Zoology, University of California Berkeley, Berkeley, CA, USA \\ ${ }^{12}$ Center for Behavioral Neuroscience, Yerkes National Primate Research Center, Emory University, Atlanta, GA, USA \\ ${ }^{13}$ Departamento de Fisiología, Facultad de Medicina, Montevideo, Uruguay \\ ${ }^{14}$ Department of Neurobiology, Physiology and Behavior, University of California Davis, CA, USA \\ ${ }^{15}$ Department of Ecology, Evolution and Environmental Biology, Columbia University, New York, NY, USA \\ ${ }^{16}$ Department of Psychology, University of California Berkeley, Berkeley, CA, USA \\ 17 Instituto de Ecología y Evolución, Facultad de Ciencias, Universidad Austral de Chile, Valdivia, Chile
}

\section{Edited by:}

Regina M. Sullivan, University of Oklahoma, USA; NYU Langone Medical Center, USA; Nathan Kline Institute for Psychiatric Research, USA

\section{Reviewed by:}

Frances A. Champagne, Columbia University, USA

Nim Tottenham, University of California Los Angeles, USA

\section{*Correspondence:}

Daniel T. Blumstein, Department of Ecology and Evolutionary Biology, University of California Los Angeles, 621 Young Drive South, Los Angeles, CA 90095-1606, USA

e-mail:marmots@ucla.edu; Loren D. Hayes, Department of Biology, University of Louisiana at Monroe, Monroe, LA 71209, USA

e-mail:Ihayes@ulm.edu

${ }^{+}$Current Address: Joseph Robert Burger, Department of Biology, University of New Mexico, Albuquerque, NM, USA.
Social interactions among conspecifics are a fundamental and adaptively significant component of the biology of numerous species. Such interactions give rise to group living as well as many of the complex forms of cooperation and conflict that occur within animal groups. Although previous conceptual models have focused on the ecological causes and fitness consequences of variation in social interactions, recent developments in endocrinology, neuroscience, and molecular genetics offer exciting opportunities to develop more integrated research programs that will facilitate new insights into the physiological causes and consequences of social variation. Here, we propose an integrative framework of social behavior that emphasizes relationships between ultimate-level function and proximate-level mechanism, thereby providing a foundation for exploring the full diversity of factors that underlie variation in social interactions, and ultimately sociality. In addition to identifying new model systems for the study of human psychopathologies, this framework provides a mechanistic basis for predicting how social behavior will change in response to environmental variation. We argue that the study of non-model organisms is essential for implementing this integrative model of social behavior because such species can be studied simultaneously in the lab and field, thereby allowing integration of rigorously controlled experimental manipulations with detailed observations of the ecological contexts in which interactions among conspecifics occur.

Keywords: integrative models of social behavior, behavioral neuroendocrinology, behavioral genetics, psychopathology, model systems

\section{INTRODUCTION}

Social behavior is comprised of interactions among conspecifics and results in relationships of variable form, duration, and function. Social interactions provide the foundation for a broad array of behavioral phenomena, including many of the complex forms of cooperation and conflict that are of particular interest to behavioral biologists (Nowak, 2006). For example, group living and communal rearing of young are forms of sociality that arise from social interactions among individuals. Sociality (broadly defined as group living) presents an apparent evolutionary paradox in that individuals may incur fitness costs by engaging in these interactions (Alexander, 1974; Griffin and West, 2002). Collectively, these phenomena form the basis for some of the most intricate and intriguing societies observed in nature (Wilson, 1975). In humans, social relationships are essential components of well-being (House et al., 1988), and may lead to both positive and negative health outcomes (Berkman, 1984; Uchino et al., 1996). 
While not all forms of social interaction are as complex or challenging to interpret as cooperative behaviors, social behavior is a fundamental attribute of the biology of many species and has been the focus of extensive research by scientists from multiple disciplines. Despite widespread application to basic and applied science, developing a comprehensive framework for explaining the proximate and ultimate bases for social interactions - a rapidly emerging theme in behavioral research (Owens, 2006) - has proven troublesome (Johnstone, 2000). Traditional models of social variation have focused primarily on the ecological and evolutionary factors that lead to specific forms of social interaction (e.g., group living: Emlen and Oring, 1977; Emlen, 1995; Brashares and Arcese, 2002; Cahan et al., 2002). However, recent advances in neuroscience, endocrinology, and genetics have generated the knowledge and the toolkit required for more integrative approaches to understanding social interactions (Young and Wang, 2004). Developing a conceptual framework that incorporates these new resources is essential; in addition to informing research at multiple levels of organization (e.g., from molecular to evolutionary processes), such advances in our understanding of social interactions should have applications to human welfare and health, including improved diagnosis and treatment several psychiatric disorders (Bartz and Hollander, 2006; Lim and Young, 2006; Bosch et al., 2009; McGraw and Young, 2010). For example, autism spectrum disorder and schizophrenia are both characterized by marked deficits in social cognition and social behavior (Couture et al., 2010), and disruptions of social relationships result in an increase in risk of depression (Zisook and Shuchter, 1991).

Here, we outline an integrative framework for studying social behavior that addresses four important elements of modern behavioral biology. First, the framework highlights recent genetic, endocrine, and neurobiological advances that are creating new opportunities to study mechanisms of social behavior in an ecological context. By so doing, the framework integrates well developed, but traditionally distinct areas of inquiry and fosters the use of new technologies to explore social interactions in non-traditional study organisms and in non-laboratory settings. Second, the framework helps generate predictions about social relationships that can be tested in either the field or the laboratory and that aid discrimination between the causes and consequences of social interactions. Third, the framework explores the diversity of mechanisms that underlie social variation, thereby facilitating identification of largescale patterns in the evolution of the genetic, endocrine, and neural bases for social behavior. Fourth, using non-traditional and natural systems is key to understanding natural variation in social behavior and sociality, and doing so will shed light on mechanisms maintaining social variation.

One outcome of the integrative approach that we describe is to shift attention to studies of new animal systems, some of which have been well studied by ecologists, but that have not previously been considered as subjects for more mechanistic studies of social relationships. Overall, this review should encourage new collaborations between behavioral biologists from multiple disciplines, thereby leading to exciting developments in our understanding of social behavior, including the social interactions that underlie multiple human disorders.

\section{LEVELS OF ANALYSIS: TINBERGEN REVISITED}

Traditional studies of social behavior have tended to follow the framework established by Tinbergen (1963), who outlined four orthogonal explanations for the diversity of behavior observed in nature: (1) immediate causation, (2) development, (3) function, and (4) evolutionary history. Immediate causes of behavior include physiological, genetic or ontogenetic factors, as well as the interactions among these aspects of an organism's biology. For instance, identifying hormones that modulate attachment formation, or the genes associated with social bonding would be studies that addressed immediate causation. Developmental explanations include any changes in behavior resulting from ontogenetic processes or experiences. For instance, identifying the role of early experience in influencing the decision about whether to remain in a natal group or disperse would be a study that addressed a developmental question. Functional causes describe how behavior currently influences survival and reproduction. For instance, demonstrating that individuals living in certain sized social groups have higher survival and reproductive success address adaptive questions. Finally, historical explanations use a species' phylogenetic relationships to generate insights into the evolutionary gain or loss of a behavioral trait. For instance, demonstrating that sociality evolved (or failed to evolve) in a particular group of organisms, might suggest a phylogenetic predisposition or constraint on sociality. Such research addresses historical explanations of sociality.

These questions (or approaches) are orthogonal (i.e., unrelated) because for any of the four questions, there are a series of mutually exclusive hypotheses that may account for them. In other words, it is logical to ask whether hormone a or hormone b potentiates attachment. It is logical to ask whether animals that live in a group could have higher survival living in a larger or smaller group. However, answering the question about the specific hormone that potentiates attachment does not influence the optimal group size, and viceversa. Thus, to a large extent, each approach is unrelated.

These four approaches to the study of behavior can be divided into two levels of analysis (Sherman, 1988). Immediate causation and development comprise proximate explanations that answer questions regarding how behaviors occur mechanistically. Function and evolutionary history comprise ultimate explanations that reflect on why behaviors have evolved or are maintained. The four explanations are complementary - not exclusive - and any trait can be studied at any (and likely all) of these level(s) of inquiry (Bolhuis and Verhulst, 2009). We propose that incorporating each of these levels of analysis will lead to a more integrative understanding of social behavior that will benefit all disciplines.

Historically, behavioral ecologists have emphasized ultimatelevel questions, while biomedical researchers have focused on proximate-level phenomena, creating a conceptual and practical divide between these research settings that includes the emergence of distinct terminologies, methodologies, and study organisms. Recently, however, traditionally field-based behavioral ecologists have re-discovered the importance of studying proximate mechanisms (e.g., genetic, physiological, neuroendocrine, and neurophysiological processes) underlying behavior in order to better understand the evolution of behavior (Stamps, 1991; Owens, 2006). This increased recognition of the importance of proximate-level research has been facilitated by technical advances that have made 
mechanistic studies more tractable and that have opened up new lines of inquiry for understanding social behavior. In particular, recent advances linking physiology, genomics, and behavior offer exciting new opportunities to integrate ultimate- and proximatelevel questions to explore social interactions, thereby forging new links between social behavior and potential causes of human behavioral dysfunction (Robinson et al., 2008). We feel strongly that likewise, biomedical research could benefit tremendously from incorporating the perspectives of behavioral ecologists to discover new model organisms and to refine experimental paradigms in an ethologically relevant manner.

\section{THE IMPORTANCE OF NATURAL POPULATIONS}

As an ethologist, Tinbergen's studies of behavior were based largely upon observations of free-living animals faced with the challenges of surviving and reproducing in complex, "real world" environments. While studies of natural populations typically lack the rigorous control of environmental and inter-individual variation characteristic of laboratory-based research, data from free-living animals are critical to a comprehensive understanding of variation in social behavior for several reasons. First, observations of free-living individuals, behaving in species-typical ways, can be used to validate data from laboratory studies by confirming that behavioral interactions observed in captivity are characteristic of those observed in natural environments (Holmes and Sherman, 1982; Schradin and Pillay, 2003). Second, when observations of captive and free-living conspecifics differ, comparisons of data obtained in these two distinct contexts can be used to generate new insights into the factors regulating behavior (Calisi and Bentley, 2009). Third, studies of free-living animals provide the ecological context required to evaluate the functional consequences of social behavior. Specifically, data from natural populations allow investigators to assess the reproductive and survival (functional) consequences of behavior under the selective conditions in which it normally occurs; in the absence of such information, it can be difficult to determine the functional and, hence, potential evolutionary significance variation in social interactions. Thus, while many of the recent endocrine, neural and genetic advances in our understanding of behavior have necessarily begun in the lab, applying these ideas and technologies to natural populations is essential to generating a complete understanding of the causes of variation in social behavior.

\section{GENETIC AND GENOMIC ADVANCES: NEW OPPORTUNITIES TO EXPLORE NATURAL SYSTEMS}

Studies of humans as well as traditional non-human animal models (e.g., Drosophila melanogaster, Caenorhabditis elegans, Mus musculus, Rattus norvegicus) have been invaluable for identifying genes involved in the regulation of social behavior (Robinson et al., 2005). Given that gene function is often conserved, we expect that numerous homologous loci await study in non-traditional model systems, thereby allowing exploration of gene expression in freeliving animals subject to variable environmental conditions. For example, in lab populations of $D$. melanogaster, the foraging gene is responsible for differences in locomotor activity related to securing food; homologues of foraging have been shown to influence the age of onset of foraging in free-living honeybees (Apis mellifera)
(Robinson et al., 2008; Amdam and Page Jr., 2010). Among humans, allelic variants of the gene Drd4 are associated with personality traits and novelty seeking; this locus appears to play a similar role in natural populations of birds, such as great tits (Parus major; Fidler et al., 2007). Finally, polymorphisms in the vasopressin receptor gene, Avprla, are associated with pair bonding behavior in both humans and prairie voles (Microtus ochrogaster, Hammock and Young, 2005; Donaldson and Young, 2008) This conservation of gene function across sometimes disparate taxonomic groups provides an important foundation for expanding studies of the genetic bases of social behavior to natural populations of animals.

At the same time, the ever-expanding toolkit for genetic research makes it increasingly possible to undertake experimental studies of the genetic mechanisms underlying social behavior. For example, use of siRNA to knock down gene expression in zebra finch (Taeniopygia guttata) has revealed that a homolog of FoxP2 (a gene thought to be involved in human language) also plays an important role in vocal learning in songbirds (Haesler et al., 2007). Viral vector-mediated gene transfer has been used to over-express genes in specific brain regions to determine gene function in species such as prairie voles, yielding critical insights into the causes of social and mating system variation across species (Lim et al., 2004; Ross et al., 2009). Transgenic technologies, although currently limited to a few species, are being developed for non-traditional model organisms as diverse as prairie voles, three-spine sticklebacks (Gasterosteus aculeatus) and non-human primates (Hosemann et al., 2004; Donaldson et al., 2009; Sasaki et al., 2009). As such technologies become easier to employ, the range of species to which they are applied should grow, yielding an increasingly rich picture of the genetic bases for variation in social behavior.

Finally, for organisms lacking a fully sequenced genome, transcriptome studies (i.e., quantification of gene expression on a genome-wide scale) provide a tractable means of identifying genes underlying social behavior. DNA microarrays for honeybees were used to develop one of the first genome-wide views of social structure (Robinson et al., 2008) and studies of ants have demonstrated that similar genes underlie social variation (Ingram et al., 2005) in both insect lineages. Microarrays have also been used in swordtails (Xiphophorus nigrensis) to determine how gene expression differs between social and sexual signals (Cummings et al., 2008) and in African cichlids (Astatotilapia burtoni) to identify candidate genes related to social behavior, including loci that are up-regulated in dominant but not subordinate individuals (Renn et al., 2008). The rapid development of high-throughput, low-cost, "next generation" genomic sequencing technologies make it increasingly feasible to explore gene activity in a variety of non-traditional animal systems.

\section{NEUROENDOCRINE ADVANCES: IMPROVING UNDERSTANDING OF SOCIAL VARIATION}

Greater understanding of how neuroendocrine processes regulate behavior represents another area in which studies of natural populations may complement our rapidly expanding knowledge of traditional animal models. In particular, predicting how neuroendocrine activity should affect the social behavior of free-living animals is central to the development of an integrative model of sociality (Nunes et al., 1999; Ryan and Vandenbergh, 2002). Below, we 
highlight several exciting areas of research into the neuroendocrine bases for social behavior. Two of these (circulating hormone levels, receptor density and expression) are pathways for which evidence is already accruing regarding neuroendocrine or neuroanatomical influences on social behavior. While few empirical data are available for the third pathway (binding globulins), this aspect of neuroendocrine function appears to hold great potential for future research into the proximate bases for social variation.

\section{CIRCULATING HORMONE LEVELS}

Much of the research linking environmental variation, neuroendocrine function, and social behavior in vertebrates has focused on circulating concentrations of steroids (Wingfield et al., 1990; Schoech et al., 2004; Pfaff, 2005), particularly glucocorticoids (Creel, 2001; Pfaff, 2005). For example, singular breeding societies with communal care of offspring (i.e., one female dominates reproduction and non-breeders care for non-descendent offspring; Silk, 2007) may be a selectively advantageous social strategy in stressful environments in which independent reproduction is rarely successful (Moehlman, 1979). Under these conditions, group members may produce lower levels of glucocorticoids when groups are at or below threshold size (Silk, 2007), which in turn reduces social stress and enhances cooperative rearing of offspring. Alternatively, social animals may experience chronically high levels of stress hormones which could have negative fitness consequences and possibly explain habitatspecific fitness outcomes of group living and the establishment of social hierarchies (Creel, 2001; Young et al., 2006; Rubenstein, 2007). Whether variation in glucocorticoids causes or results from social variation needs experimental demonstration (Rubenstein and Shen, 2009). There is some evidence of reduced androgens in non-breeding male alloparents, but as with glucocorticoids, patterns of androgen variation are not consistent across species (Schoech et al., 2004). For example, in striped mice (Rhabdomys pumilio - a socially flexible species in which males exhibit alternative mating tactics and varying levels of parental care-subordinate "roamer" males have higher levels of testosterone than dominant territorial males (Schradin et al., 2009). There is also some evidence that prolactin may play a causal role in subordinate helping behavior in some birds (Buntin, 1996; Schoech et al., 2004).

\section{RECEPTOR DENSITY AND EXPRESSION}

In rodents, intraspecific variation in social organization and in behaviors such as social bonding and parental care has been linked to variation in neuropeptide receptor densities in the brain (Hammock and Young, 2004; Olazábal and Young, 2006a,b; Beery et al., 2008). Highly social and monogamous species have oxytocin and vasopressin receptors concentrated in regions of the brain associated with reward and reinforcement, while non-monogamous species do not (Young and Wang, 2004). Viral vector gene transfer has been used to manipulate neuropeptide receptor expression in these brain regions in voles (Microtus spp.), thereby demonstrating a causal link between receptor expression and these aspects of behavior (Lim et al., 2004). At a genetic level, polymorphisms in the promoter regions of the genes encoding these receptors appear to contribute to diversity in receptor expression patterns (Hammock and Young, 2004). Oxytocin-like receptors may also influence sociality in birds (Goodson et al., 2009). The remarkable plasticity of the oxytocin and vasopressin receptor systems provides a potential mechanism for creating diversity in social phenotypes of both males and females. Future studies are needed to determine the relevance of these receptor systems in shaping social and reproductive interactions in natural populations of other taxa. Species with populations that exhibit intraspecific geographic variation in social mating systems (Roberts et al., 1998) may be particularly strong candidates to study variation in neuropeptide systems.

\section{BINDING GLOBULINS}

Steroid-binding proteins are glycoproteins that transport hormones of the hypothalamic-pituitary-adrenal (HPA) and hypothalamicpituitary-gonadal (HPG) axes to target tissues (Westphal, 1983; Breuner and Orchinik, 2002). The function of binding globulins is much debated. It is not clear whether binding globulins act simply to transport steroids to target tissues (carrier hypothesis) or whether they act like a sponge to bind excess steroids to prevent them from reaching target tissues, thereby buffering tissues from high circulating steroid levels (buffer hypothesis) (Romero, 2002). Moreover, the function of steroid-binding proteins could differ among taxa. For example, in contrast to mammals, birds appear to lack a sex steroid-specific binding globulin; instead sex steroids (e.g., testosterone) are bound to corticosteroid-binding globulins (CBG, Deviche et al., 2001). In captive rats, subordinate individuals had lower CBG concentrations than dominant individuals (Spencer et al., 1996; Stefanski, 2000) while in horses social stress caused a decrease in CBG binding capacity (Alexander and Irvine, 1998). These results suggest a potentially crucial link between stress, CBG, and inter-individual variation in social behavior. Consequently, the role of CBG and other binding globulins deserves further consideration in studies of vertebrate social behavior.

Continued research into how neuroendocrine mechanisms influence social behavior in diverse organisms will lead to improved understanding of the evolution of mechanistic diversity and will ultimately allow us to make more concrete predictions. These predictive abilities will emerge from the study of a diversity of species, engaged in a diversity of social behaviors.

\section{AN INTEGRATIVE APPROACH: GUIDING FUTURE RESEARCH}

Figure 1 illustrates how environmental conditions and natural selection may interact to shape the proximate mechanisms underlying variation in social interactions and, in turn, how those mechanisms may affect the fitness consequences of differences in social behavior. Pathways link social and ecological responses to physiological and behavioral changes in the individual. We believe that both disciplines (behavioral ecology and biomedical research) could benefit tremendously from adopting this integrative perspective.

\section{INTEGRATIVE RESEARCH DIRECTIONS}

Below, we highlight several important areas of research that are being enhanced by an integrative approach to social behavior; we expect that other, new lines of inquiry will emerge as additional mechanisms and techniques are incorporated into an integrative framework such as we propose. To underscore the utility of this framework in uniting traditional and emerging perspectives on social behavior, we cast our review in terms of the four orthogonal research questions outlined by Tinbergen nearly 50 years ago: 


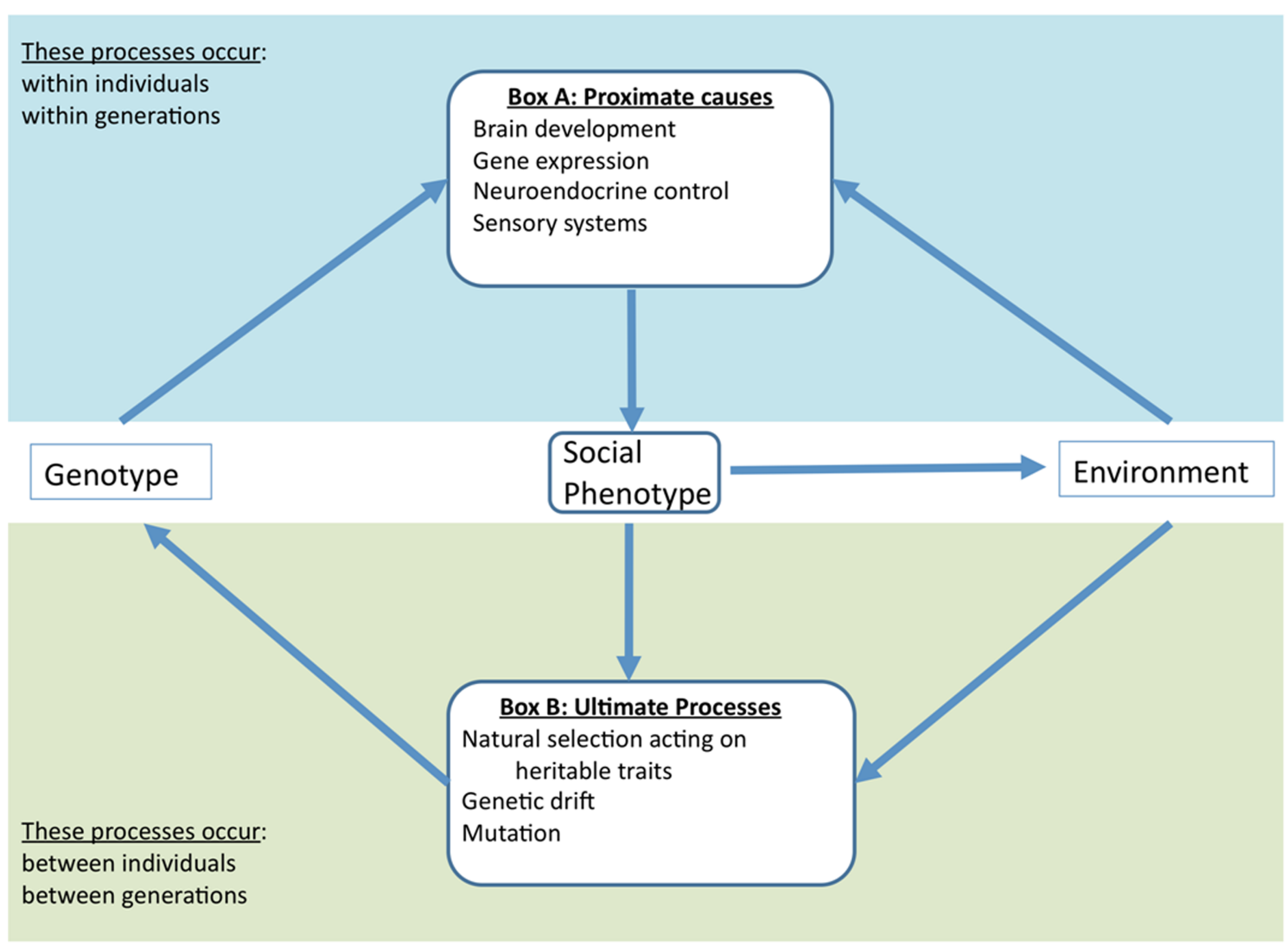

FIGURE 1 |An integrative framework for studying social behavior. This framework is consistent with the recursive evolutionary paradigm (Feder et al., 2000) wherein the genotype of an individual works in concert with the environment to produce a given phenotype (Box A). This has adaptive and non-adaptive consequences that determine the genotypes in the next generation (Box B). Social phenotypes may influence the environment in multiple ways, indicating a dynamic bi-directional relationship that can affect processes in both boxes. Since the environment in turn influences both proximate mechanisms and ultimate processes, it is important to study both to gain an integrative understanding of social behavior. For example, if a social behavior decreases predation threat, behavioral biologists should examine how that decrease affects the neuroendocrine mechanisms underlying that behavior in addition to how it affects the selective landscape. Moreover, because proximate mechanisms (Box A) are themselves subject to evolutionary dynamics (Box B), there is a need for research measuring selection on and heritability of that neuroendocrine mechanism rather than simply the direct effect on the social behavior. This model, while not exhaustive, provides a framework and guidance for synthetic research of sociality.
(1) Immediate causation. The environment may contribute to intraspecific variation in behavioral phenotypes by altering proximate mechanisms governing behavior, including allelic variation, gene expression, and neural activity. For example, prairie voles found in ecologically distinct populations exhibit marked differences in social behavior (Roberts et al., 1998). Young and Wang (2004) have shown that this variation in vole social behavior is linked to variation in oxytocin/vasopressin receptor densities in the brain, with the expression of these receptors being mediated by the oxtr and avprla genes. Our model integrates this information, generating the following predictions: (a) the immediate ecological causes of habitat-specific social behavior include factors such as the distribution of food resources or habitat openness, (b) differential selection resulting from this ecological variation leads to population-level differences in the frequency of avpr1a alleles, and (c) allelic differences in avrpla gene expression explain populationspecific neuropeptide receptor densities.
(2) Ontogeny. Variation in the physical or social environment may influence the timing of ontogenetic changes (nervous system development, endocrine function, gene expression) that mediate social behavior. For example, natal philopatry (remaining in the social group one was born into) is widely recognized as an important process leading to the formation of social groups (Emlen, 1995). The ecological causes of natal philopatry are usually attributed to benefits of philopatry (e.g., indirect fitness) or ecological constraints on dispersal (e.g., habitat saturation). Nunes et al. (1999) demonstrated that Belding's ground squirrel (Urocitellus beldingi) dispersal is mediated by organizational effects of testosterone during early post-natal development. Within such a mammalian system, our framework could integrate these ideas, generating the following predictions: (a) limited resources lead to reduced hypothalamic production of $\mathrm{GnRH}$, pituitary responsiveness to $\mathrm{GnRH}$, and luteinizing hormone receptor expression during early post-natal development, resulting in fewer dispersers and greater natal philopatry, (b) individuals 
staying in the group have higher inclusive fitness than those that disperse or do not form groups, and (c) social group formation decreases testosterone during early post-natal development, resulting in greater dispersal and reduced philopatry. Other areas of exploration include how (i) ecology influences maternal condition and, therefore, offspring development and adult behavior (e.g., intrauterine position effects on social behaviors; Ryan and Vandenbergh, 2002) and (ii) ecological and social variation influence the genetic and hormonal pathways leading to the development of alloparental care.

(3) Function. The fitness consequences of social behavior are often habitat-specific (Silk, 2007). Individuals encounter environmental variation and respond accordingly both during ontogeny (that determines phenotype) and through day-to-day, seasonal and facultative experience. The resulting social behavior (a phenotype) has costs and benefits, the magnitudes of which determine fitness (lifetime reproductive success). These ideas can be tested in the context of social behavior such as group foraging, which is thought to reduce the risk of predation. Under this hypothesis, social foraging is selectively advantageous in open habitats or in habitats with abundant predators (Ebensperger, 2001; Brashares and Arcese, 2002). However, social foraging has costs and thus, may occur less in habitats with low predation pressure. Different neural and sensory pathways are expected to be activated in these ecological and social conditions (sensu Hermes et al., 2009). For example, if the function of social foraging is to reduce predation risk, then reduced allostatic loads are expected when individuals forage together. This hypothesis predicts that (a) individuals have higher circulating glucocorticoid levels in populations with abundant predators and (b) circulating glucocorticoid levels decrease with increasing number of individuals per foraging group in populations with high levels of predation risk.

(4) Evolutionary history. While such studies are largely lacking, each of the above topics can be addressed through comparative studies conducted in a phylogenetic context. By examining patterns of mechanistic diversity across a broad array of taxa for which phylogenetic relationships are known, it should be possible to identify previously unrecognized examples of evolutionary divergence, convergence, and conservation of mechanisms of social behavior. Social phenotypes can be constrained by the genetic architecture of proximate mechanisms, which is dependent on evolutionary history. Once these phenomena have been comprehensively characterized, it will be possible to study the evolution of mechanism in novel and comprehensive ways. In particular, once these evolutionary patterns have been identified, we will be able to complete much more meaningful analyses of the ways in which ecological and life history factors affect mechanisms of social behavior, thereby linking studies of mechanism back to the ultimate-level questions most often addressed by behavioral ecologists. For example, as we gather more information on the link between mating systems and the expression of neuropeptide receptors underlying social variation, it will be possible to employ phylogentically controlled comparative approaches. Based on ecological (Emlen and Oring, 1977) and neuroanatomical (Young and Wang, 2004) theory, we expect that across taxa, the expression of neuropeptide receptors underlying mating systems (e.g., oxytocin, vasopressin) will be similar in species found in similar habitats.

\section{AN EVOLUTIONARY CONTEXT FOR UNDERSTANDING THE MECHANISMS OF SOCIAL VARIATION}

As noted above, an evolutionary approach to studies of the proximate mechanisms underlying social behavior may lead to new, comparative insights into how such mechanisms evolve and are maintained in animal populations. We believe that this outcome of an integrated approach to social behavior is so important that we wish to elaborate upon this topic with the following examples:

(1) Divergence. There are multiple ways to solve a mechanistic problem, leading to the potential for considerable evolutionary divergence in the mechanistic bases for social behavior. This variation may be evident, for example, in the ways that hormones are regulated; while some endocrine mechanisms are modulated at the secretory level, others are modulated at the level of receptor number or sensitivity (Bamberger et al., 1996). Temporal variation in neuroendocrine mechanisms is also evident. For example, in some birds, aggression (e.g., territory defense) during the mating season is regulated by circulating testosterone while territoriality during the non-breeding season is regulated by localized (i.e., noncirculating) production of testosterone and estradiol produced within the brain (Soma et al., 2008).

(2) Convergence. The variety of mechanisms associated with social behavior also raises the possibility of evolutionary convergence in hormonal and other proximate solutions to behavioral challenges. As a potential example of such convergence, bird song and fish acoustical signals - both of which are involved in territory defense - involve very different sound-production organs (syrinx, swim bladder, electric organs), yet both systems are modulated by androgens and are regulated by distinct but similarly functioning neural circuitry (Smith et al., 1997; Zakon and Dunlap, 1999; Bass et al., 2008).

(3) Conservation of function. Particularly effective mechanisms may be retained over time and through speciation events because of the adaptive benefits that they confer. For example, oxytocin and vasopressin (or their homologs) are involved in maintaining affiliative relationships in songbirds (Goodson et al., 2009) and in voles (Donaldson and Young, 2008). Similarly, glucocorticoids have a generalized role in mobilizing energy and redirecting behavior in many vertebrates and across many different social contexts (Denver, 2009). These observations suggest that these endocrine systems have deep evolutionary histories and that their functions have been conserved for extended periods of vertebrate evolution.

In general, these patterns will only emerge from a comparative, evolutionary approach. However, more information on the mechanisms of social behaviors is needed from a diverse range of taxa before such comparisons can be made. At this time, we lack 
evidence of mechanisms underlying social behaviors from sufficient taxa - until this information is discovered such comparative, evolutionary approaches are unattainable. Thus, we argue that behavioral ecologists and neuroscientists need to engage in more collaboration aimed at identifying the mechanisms of social behaviors in new model organisms, expanding on the limited number of traditional model organisms used to date.

\section{REDEFINING MODEL ORGANISMS}

Natural selection has generated an extraordinary diversity of behavioral adaptations to environmental variation. Behavioral ecologists have exploited this diversity to determine the ecological causes and fitness consequences of variation in social behavior in a wide range of species. However, our understanding of the genetic and neuroendocrine basis of social behavior is still limited and has been derived primarily from laboratory studies of inbred lines of classic model organisms (e.g., mice, rats, and fruit flies; Sokolowski, 2010). Indeed, there may be non-model systems that might be better models than these classic model organisms. To begin to use our integrative model to gain a comprehensive understanding of social interactions, it is time to rethink the traditional definition of a model organism and to begin developing new model systems in which it is possible to study ultimate-level questions of function as well as the proximate-level neurobiological and genetic mechanisms that underlie social variation.

An ideal model system should exhibit marked spatial or temporal variation in social behavior that can be studied quantitatively both in the laboratory and in natural (or semi-natural) environments. Traditionally, traits that have made an organism valuable to laboratory studies have included short generation times, regular reproduction in the laboratory environment, ease of handling for experimental manipulations, and availability of tools for characterizing genetic, neural, and endocrine mechanisms. However, some free-living species might illustrate the ways human populations have spread throughout world, and hence they might provide an ideal model to analyze social variation and behavioral mechanisms that are uniquely shaped by this dispersal history and subsequent adaptation to a variety of ecological situations. As genetic and other technologies improve, the ability to study mechanisms in less traditional model species increases (Donaldson and Young, 2008; McGraw and Young, 2010). Other desirable traits such as ease of capture and observation in the wild will ensure that as these technologies become increasingly available and affordable.

\section{RELEVANCE TO HUMAN SOCIAL BEHAVIOR}

The integrative approach we suggest, coupled with the development of new model organisms for the study of variation in social behavior may provide a powerful means to translate research findings into improved understanding human social cognitive function (Ebstein et al., 2010; Insel, 2010). A variety of neuropsychiatric disorders are characterized by disruptions in social behavior and social cognition,

\section{REFERENCES}

Alexander, R. D. (1974). The evolution of social behavior. Annu. Rev. Ecol. Syst. 5, 325-383.

Alexander, S. L., and Irvine, C. H. G. (1998). The effect of social stress on adrenal

including depression, autism spectrum disorders, bipolar disorders, obsessive-compulsive disorders, and schizophrenia. Therefore, integrative research using more accurate animal models of social behavior may lead to the development of treatment strategies for psychopathologies. In other words, the perspectives of behavioral ecology may be lead to discoveries of animal models that are ideally suited for addressing questions relevant to psychiatry. For example, discoveries of the role of oxytocin in social attachment in socially monogamous prairie voles have already led to clinical therapy trials for the enhancement of social cognitive function in autism spectrum disorders through the use of oxytocin pharmacotherapies (Opar, 2008). Thus, by adopting a more ecological and evolutionary approach to biomedical research, we should enhance our biomedical discoveries.

\section{CONCLUSIONS}

Our integrative framework (Figure 1) has broad implications for the study of social behavior. A fully integrative model for sociality has been the "holy grail" of behavioral ecologists studying social relationships among individuals. By conducting studies with explicit links between proximate and ultimate levels of analysis, we gain a comprehensive and integrative understanding of these relationships, an advance that could generate a paradigm shift studying the study of social behavior. Additionally, this approach has many applications. First, an integrative view of sociality that includes genetic, neural, and endocrine mechanisms will provide insights into evolutionary potential and thus provides a powerful tool for predicting species responses to environmental change. Second, such a fundamentally integrative understanding can yield insights into human psychopathological disorders that may improve treatment of these conditions. Third, an understanding of the links between ecological variation, mechanism, and sociality can lead to improvements in animal husbandry and welfare as part of both endangered species management and animal production. To achieve these benefits, we must train our next generation of students in integrative approaches to behavior and create a culture of interdisciplinary, collaborative work. This requires financial and logistical support by universities, medical facilities, and funding agencies. While difficult, these efforts will yield extraordinary benefits to the study of social behavior.

\section{ACKNOWLEDGMENTS}

This manuscript is a product of an international working group that convened 4-8 August 2009 at Pontificia Universidad Católica de Chile in Santiago, Chile. The working group was funded by a National Science Foundation international grant to Daniel T. Blumstein (\#0901045) and Loren D. Hayes (\#0901056), a grant from the Departamento de Relaciones Internacionales de CONICYT to Luis A. Ebensperger, and MIDEPLAN ICM-P05-002, and PFB-23CONICYT-IEB funds to Rodrigo A. Vásquez. Additionally, Gabriela González-Mariscal was supported by CINESTAV. After the four workshop organizers, authors are listed alphabetically.

physiology of honeybee societies. Anim. Behav. 79, 973-980.

axis activity in horses: the importance of monitoring corticosteroid-binding globulin capacity. J. Endocrinol. 157, 425-432.

Amdam, G. V., and Page, R. E. Jr. (2010). The developmental genetics and
Bamberger, C. M., Schulte, H. M., and Chrousos, G. P. (1996). Molecular determinants of glucocorticoid receptor function and tissue sensitivity to glucocorticoids. Endocr. Rev. 17, 245-261.

Bartz, J. A., and Hollander, E. (2006). The neuroscience of affiliation: forging links between basic and clinical research on neuropeptides 
and social behavior. Horm. Behav. 50, 518-528.

Bass, A. H., Gilland, E. H., and Baker, R. (2008). Evolutionary origins for social vocalization in a vertebrate hindbrainspinal compartment. Science 321, 417-421.

Beery, A. K., Lacey, E. A., and Francis, D. D. (2008). Oxytocin and vasopressin receptor distributions in a solitary and a social species of tuco-tuco (Ctenomys haigi and Ctenomys sociabilis).J. Comp. Neurol. 507, 1847-1859.

Berkman, L. F. (1984). Assessing the physical health effects of social networks and social support. Annu. Rev. Public Health 5, 413-432.

Bolhuis, J. J., and Verhulst, S. (2009). Tinbergen's Legacy: Function and Mechanism in Behavioral Biology. New York: Cambridge University Press.

Bosch, O. J., Nair, H. P., Ahern, T. D., Neumann, I. D., and Young, L. J. (2009). The CRF system mediates the emergence of depressivelike behavior following loss of a partner in a monogamous rodent. Neuropsychopharmacology 34, 1406-1415.

Brashares, J. S., and Arcese, P. (2002). Role of forage, habitat and predation in the behavioural plasticity of a small African antelope. J. Anim. Ecol. $71,628-638$.

Breuner, C. W., and Orchinik, M. (2002). Beyond carrier proteins: plasma binding proteins as mediators of corticosteroid action in vertebrates. $J$. Endocrinol. 175, 99-112.

Buntin,J.D. (1996). Neural and hormonal control of parental behavior in birds. Adv. Study Behav. 25, 161-213.

Cahan, S. H., Blumstein, D. T., Sundström, L., Liebig, J., and Griffin, A. (2002). Social trajectories and the evolution of social behavior. Oikos 96, 206-216.

Calisi, R. M., and Bentley, G. E. (2009). Lab and field experiments: are they the same animal? Horm. Behav. 56, 1-10.

Couture, S. M., Penn, D. L., Losh, M., Adolphs, R., Hurley, R., and Piven, J. (2009). Comparision of social cognitive functioning in schizophrenia and high functioning autism: more convergence than divergence. Psychol. Med. 40, 569-579.

Creel, S. (2001). Social dominance and stress hormones. Trends Ecol. Evol. 16, 491-497.

Cummings, M.E., Larkins-Ford, J., Reilly, C. R. L., Wong, R. Y., Ramsey, M., and Hofmann, H. A. (2008). Sexual and social stimuli elicit rapid and contrasting genomic responses. Proc. R. Soc. Lond., B, Biol. Sci. 275, 393-402.

Denver, R. J. (2009). Structural and functional evolution of vertebrate neuroendocrine stress systems. Ann. N. Y. Acad. Sci. 1163, 1-16.
Deviche, P., Breuner, C., and Orchinik, M. (2001). Testosterone, corticosterone, and photoperiod interact to regulate plasma levels of binding globulin and free steroid hormone in Dark-eyed Juncos, Junco hyemalis. Gen. Comp. Endocrinol. 122, 67-77.

Donaldson, Z. R., Yang, S. H., Chan, A. W., and Young, L. J. (2009). Production of germline transgenic prairie voles (Microtus ochrogaster) using lentiviral vectors. Biol. Reprod. 81, 1189-1195.

Donaldson, Z. R., and Young, L. J. (2008). Oxytocin, vasopressin, and the neurogenetics of sociality. Science 322, 900-904.

Ebensperger, L. A. (2001). A review of the evolutionary causes of rodent groupliving. Acta Theriol. 46, 115-144.

Ebstein, R.P., Israel, S., Chew, S. H.,Zhong, S., and Knafo, A. (2010). Genetics of human social behavior. Neuron 65 , 831-844.

Emlen, S. T. (1995). An evolutionary theory of the family. Proc. Natl. Acad. Sci. U.S.A. 92, 8092-8099.

Emlen, S. T., and Oring, L. W. (1977). Ecology, sexual selection, and the evolution of mating systems. Science 197, 215-222.

Feder, M. E., Bennett, A. F., and Huey, R. B. (2000). Evolutionary psychology. Annu. Rev. Ecol. Syst. 31, 315-341.

Fidler,A.E., van Oers, K., Drent, P.J., Kuhn, S., Mueller, J. C., and Kempenaers, B. (2007). Drd4 gene polymorphisms are associated with personality variation in a passerine bird. Proc. R. Soc. Lond., B, Biol. Sci. 274, 1685-1691.

Goodson, J. L., Schrock, S. E., Klatt, J. D., Kabelik, D., and Kingsbury, M. A. (2009). Mesotocin and nonapeptide receptors promote estrilid flocking behavior. Science 325, 862-866.

Griffin, A. S., and West, S. A. (2002). Kin selection: fact and fiction. Trends Ecol. Evol. 17, 15-21.

Haesler, S., Rochefort, C., Georgi, B., Licznerski, P., Osten, P., and Scharff, C. (2007). Incomplete and inaccurate vocal imitation after knockdown of FoxP2 in songbird basal ganglia nucleus area X. PLoS Biol. 5, e321. doi: 10.1371/journal.pbio.0050321.

Hammock, E. A. D., and Young, L. J. (2004). Functional microsatellite polymorphisms associated with divergent social structure in vole species. Mol. Biol. Evol. 21, 1057-1063.

Hammock,E.A.D., and Young,L.J. (2005). Microsatellite instability generates diversity in brain and sociobehavioral traits. Science 308, 1630-1634.

Hermes, G. L., Delgado, B., Tretiakova, M., Cavigelli, S. A., Krausz, T., Conzen, S. D., and McClintock, M. K. (2009). Social isolation dysregulates endocrine and behavioral stress while increasing malignant burden of spontaneous mammary tumors. Proc. Natl. Acad. Sci. U.S.A. 106, 22393-22398.

Holmes, W. G., and Sherman, P.W. (1982). The ontogeny of kin recognition in two species of ground squirrels. Am. Zoologist 22, 491-517.

Hosemann, K. E., Colosimo, P. F., Summers, B. R., and Kingsley, D. M. (2004). A simple and efficient microinjection protocol for making transgenic sticklebacks. Behaviour 141, 1345-1355.

House, J. S., Landis, K. R., and Umberson, D. (1988). Social relationships and health. Science 241, 540-545.

Ingram, K. K., Oefner, P., and Gordon, D. M. (2005). Task-specific expression of the foraging gene in harvester ants. Mol. Ecol. 14, 813-818.

Insel, T. R. (2010). The challenge of translation in social neuroscience: a review of oxytocin, vasopressin, and affiliative behavior. Neuron 65, 768-779.

Johnstone, R. A. (2000). Models of reproductive skew: a review and synthesis. Ethology 106, 5-26.

Lim, M.M., Wang, Z., Olazábal, D.E., Ren, X., Terwilliger, E. F., and Young, L. J. (2004). Enhanced partner preference in a promiscuous species by manipulating the expression of a single gene. Nature 429, 754-757.

Lim, M. M., and Young, L. J. (2006). Neuropeptidergic regulation of affiliative behavior and social bonding in animals. Horm. Behav. 50, 506-517.

McGraw, L. A., and Young, L. J. (2010). The prairie vole (Microtus ochrogaster): an emerging model organism for understanding the social brain. Trends Neurosci. 33: 103-109.

Moehlman, P. (1979). Jackal helpers and pup survival. Nature 277, 382-383.

Nowak, M. A. (2006). Five rules for the evolution of cooperation. Science 314 1560-1563.

Nunes, S., Duniec, T. R., Schweppe, S. A., and Holekamp, K. E. (1999). Energetic and endocrine mediation of natal dispersal behavior in Belding's ground squirrels. Horm. Behav. 35, 113-124.

Olazábal, D. E., and Young, L. J. (2006a). Species and individual differences in juvenile female alloparental care are associated with oxytocin receptor density in the striatum and the lateral septum. Horm. Behav. 49, 681-687.

Olazábal, D. E., and Young, L. J. (2006b). Oxytocin receptors in the nucleus accumbens facilitate "spontaneous" maternal behavior in adult female prairie voles. Neuroscience 141, 559-568.

Opar, A. (2008). Search for potential autism treatments turns to "trust hormone". Nat. Med. 14, 353.

Owens, I. P. F. (2006). Where is behavioural ecology going? Trends Ecol. Evol. 21, 356-361.
Pfaff, D. (2005). Hormones, Brain, and Behavior, Vol. 5. Boston: Academic Press.

Renn, S. C. P., Aubin-Horth, N., and Hofmann, H. A. (2008). Fish and chips: functional genomics of social plasticity in an African cichlid fish. $J$. Exp. Biol. 211, 3041-3056.

Roberts, R. L., Cushing, B. S., and Carter, C. S. (1998). Intraspecific variation in the induction of female sexual receptivity in prairie voles. Physiol. Behav. 64, 209-212.

Robinson, G. E., Fernald, R. D., and Clayton, D. F. (2008). Genes and social behavior. Science 322, 896-900.

Robinson, G. E., Grozinger, C. M., and Whitfield,C.W.(2005).Sociogenomics: social life in molecular terms. Nat. Rev. Genet. 6, 257-270.

Romero, L.M. (2002). Seasonal changes in plasma glucocorticoid concentrations in free-living vertebrates. Gen. Comp. Endocrinol. 128, 1-24.

Ross, H. E., Freeman, S. M., Spiegel, L. L., Ren, X., Terwilliger, E. F., and Young, L. J. (2009). Variation in oxytocin receptor density in the nucleus accumbens has differential effects on affiliative behaviors in monogamous and polygamous voles. J. Neurosci. 29, 1312-1318.

Rubenstein, D. R. (2007). Stress hormones and sociality: integrating social and environmental stressors. Proc. R. Soc. Lond., B, Biol. Sci. 274, 967-975.

Rubenstein, D. R., and Shen, S.-F. (2009). Reproductive conflict and the costs of social status in cooperatively breeding vertebrates. Am. Nat. 173, 650-661.

Ryan, B. C., and Vandenbergh, J. G. (2002). Intrauterine position effects. Neurosci. Biobehav. Rev. 26, 665-678.

Sasaki, E., Suemizu, H., Shimada, A., Hanazawa, K., Oiwa, R., Kamioka, M., Tomioka, I., Sotomaru, Y., Hirakawa, R., Eto, T., Shiozawa, S., Maeda, T., Ito, M., Ito, R., Kito, C., Yagihashi, C., Kawai, K., Miyoshi, H., Tanioka, Y., Tamaoki, N., Habu, S., Okano, H., and Nomura, T. (2009). Generation of transgenic non-human primates with germline transmission. Nature 459, 523-527.

Schoech, S. J., Reynolds, S. J. and Boughton, R. K. (2004). "Endocrinology," in Ecology and Evolution of Cooperative Breeding in Birds, eds W. D. Koenig and J. Dickenson (Cambridge: Cambridge University Press), 128-141.

Schradin, C. and Pillay, N. (2003). Paternal care in the social and diurnal striped mouse (Rhabdomys pumilio): laboratory and field evidence. $J$. Comp. Psychol. 117, 317-324.

Schradin, C., Scantlebury, M., Pillay, N., and Konig, B. (2009). Testosterone 
levels in dominant sociable males are lower than in solitary roamers: physiological difference between three male reproductive tactics in a sociably flexible mammal. Am. Nat. 173, 376-388.

Sherman, P.W. (1988). The levels of analysis. Anim. Behav. 36, 616-619.

Silk, J. B. (2007). The adaptive value of sociality in mammalian groups. Philos. Trans. R. Soc. Lond., B, Biol. Sci. 362, 539-559.

Smith, G. T., Brenowitz, E. A., Beecher, M. D., and Wingfield, J. C. (1997). Seasonal changes in testosterone, neural attributes of song control nuclei, and song structure in wild songbirds. J. Neurosci. 17, 6001-6010.

Sokolowski, M. B. (2010). Social interactions in "simple" model systems. Neuron 65, 780-794.

Soma, K. K., Scotti, M. A. L., Newman, A. E.M, Charlier, T. D., and Demas, G. E. (2008). Novel mechanisms for neuroendocrine regulation of aggression. Front. Neuroendocrinol. 29, 476-489.

Spencer, R. L., Miller, A. H., Moday, H., McEwen, B. S., Blanchard, R. J., Blanchard, D. C., and Sakai, R. R.
(1996). Chronic social stress produces reductions in available splenic type II corticosteroid receptor binding and plasma corticosteroid binding globulin levels. Psychoneuroendocrinology 21, 95-109.

Stamps, J. A. (1991). Why evolutionary issues are reviving interest in proximate behavioral mechanisms. Am. Zool. 31, 338-348.

Stefanski, V. (2000). Social stress in laboratory rats: hormonal responses and immune cell distribution. Psychoneuroendocrinology 25, 389-406.

Tinbergen, N. (1963). On aims and methods of ethology. Z. Tierpsychol. 20, 410-433.

Uchino, B. N., Cacioppo, J. T., and Kiecolt-Glaser, J. K. (1996). The relationship between social support and physiological processes: a review with emphasis on underlying mechanisms and implications for health. Psychol. Bull. 119, 488-531.

Westphal, U. (1983). Steroid-protein interaction: from past to present. $J$. Steroid Biochem. 19, 1-15.

Wilson, E. O. (1975). Sociobiology: The New Synthesis. Cambridge: Belknap Press of Harvard University Press.
Wingfield, J. C., Hegner, R. E., Dufty, A. M. Jr., and Ball, G.F. (1990). The "challenge hypothesis": theoretical implications for patterns of testosterone secretion, mating systems, and breeding strategies. Am. Nat. 136, 829-846.

Young, A. J., Carlson, A. A., Monfort, S. L., Russell, A. F., Bennett, N. C., and Clutton-Brock, T. (2006). Stress and the suppression of subordinate reproduction in cooperatively breeding meerkats. Proc. Natl. Acad. Sci. U.S.A. 103, 12005-12010.

Young, L. J., and Wang, Z. (2004). The neurobiology of pair bonding. Nat. Neurosci. 7, 1048-1054.

Zakon, H., and Dunlap, K. D. (1999). Sex steroids and communication signals in electric fish: a tale of two species. Brain Behav. Evol. 54, 61-69.

Zisook, S., and Shuchter, S. R. (1991). Depression through the first year after the death of a spouse. Am. J. Psychiatry 148, 1346-1352.

Conflict of Interest Statement: The authors declare that the research was conducted in the absence of any commercial or financial relationships that could be construed as a potential conflict of interest.
Received: 28 April 2010; paper pending published: 17 May 2010; accepted: 22 May 2010; published online: 28 June 2010.

Citation: Blumstein DT, Ebensperger LA, Hayes LD, Vásquez RA, Ahern TH, Burger JR, Dolezal AG, Dosmann A, GonzálezMariscal G, Harris BN, Herrera EA, Lacey EA, Mateo J, McGraw LA, Olazábal D, Ramenofsky M, Rubenstein DR, SakhaiSA, Saltzman W, Sainz-Borgo C, Soto-Gamboa $M$, Stewart ML, Wey TW, Wingfield JC and Young LJ (2010) Toward an integrative understanding of social behavior: new models and new opportunities. Front. Behav. Neurosci. 4:34. doi: 10.3389/ fnbeh.2010.00034

Copyright $\Subset 2010$ Blumstein, Ebensperger, Hayes, Vásquez, Ahern, Burger, Dolezal, Dosmann, González-Mariscal, Harris, Herrera, Lacey, Mateo, McGraw, Olazábal, Ramenofsky, Rubenstein, Sakhai, Saltzman, Sainz-Borgo, Soto-Gamboa, Stewart, Wey, Wingfield and Young. This is an open-access article subject to an exclusive license agreement between the authors and the Frontiers Research Foundation, which permits unrestricted use, distribution, and reproduction in any medium, provided the original authors and source are credited. 